\title{
Energy demand and carbon emission peak forecasting of Beijing based on leap energy simulation method
}

\author{
Wang J.1,2*, Cai H., ${ }^{3,4}$ and Li L. ${ }^{5}$ \\ ${ }^{1}$ School of Economics and Management, North China Electric Power University, Beijing 102206, China \\ ${ }^{2}$ Beijing Key Laboratory of New Energy and Low-carbon Development, North China Electric Power University, Beijing 102206, China \\ ${ }^{3}$ School of Industrial Engineering, Purdue University, West Lafayette, IN 47907, USA \\ ${ }^{4}$ Environmental and Ecological Engineering, Purdue University, West Lafayette, IN 47907, USA \\ ${ }^{5}$ School of Economics and Management, Beijing Information Science \& Technology University, Beijing 100085, China \\ Received: 02/07/2020, Accepted: 04/08/2020, Available online: 22/10/2020 \\ *to whom all correspondence should be addressed: e-mail: hbdlwjj@126.com \\ https://doi.org/10.30955/gnj.003387
}

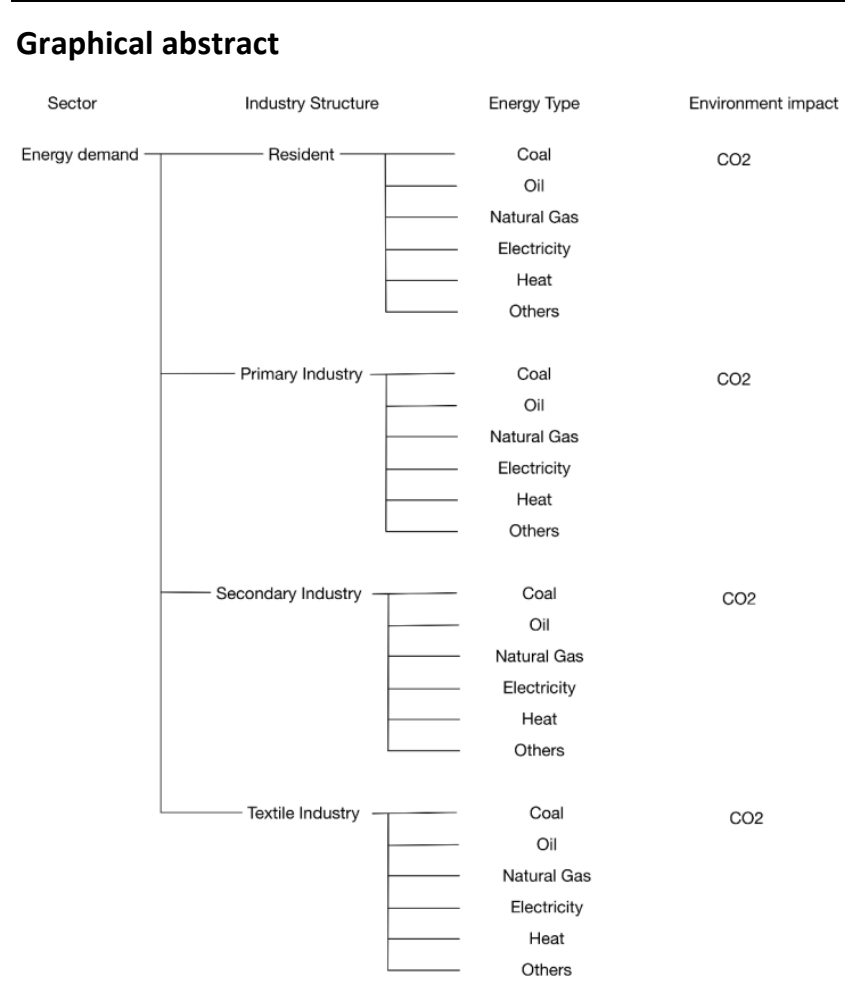

Abstract

The long-term forecasting of the energy demand is an important issue of an area's sustainable development, especially for mega cities such as Beijing. Beijing is changing its energy supply strategy to depend on energy imports from other provinces due to the city's long-term low carbon sustainable development plan. Beijing has promised that it will reach the peak value of energy consumption by 2050 and the peak value of the carbon emissions by 2030 . To understand whether this can be achieved, this study built an energy demand simulation model using the LEAP with different development scenarios. The results show that, the peak value of Beijing's energy demand is between 108.25 and 131.74 Mtce during the period of 2044 to 2048, while the peak value of carbon emissions is between 134 and 139.38 million tons in 2025 . We also find that adjusting the industry structure and improving the tertiary industry's energy usage efficiency can be efficient ways to reduce energy consumption. These approaches not only reduce the negative influence of the economic development, but also achieve the energy saving and carbon emission reducing requirements. This study provides an interpretation of the implications for the future energy and climate policies of Beijing.

Keywords: Energy demand, carbon emissions, energy consumption, energy forecasting, LEAP.

\section{Introduction}

Energy is one of the most important and necessary materials for urban development and industrial production, especially for mega cities supporting a large population. Therefore, energy supply and energy consumption forecasting are a key issue related to the social and economic development. Beijing, as the capital of China, is not only China's political and cultural centre, but also a highly developed economy. At the end of 2013, Beijing's resident population had arrived 211.48 million. Its GDP had reached 195.06 billion Chinese yuan, which increased 7.7\% compared to the value of 2012. Additionally, the city's motor vehicle ownership has reached 5.437 million ( $\mathrm{Wu}$ and $\mathrm{Xu}, 2013$ ). With its rapid economic growth and the sharp rise of vehicle ownership, Beijing's energy consumption is also increasing fast. At the end of 2013, Beijing's energy consumption has reached about 73.54 Mtce (million tons of standard coal equivalents), at an average growth rate of 2.46 in the past five years. Beijing has announced that it will reach the peak value of energy consumption by 2050 and the peak value of the carbon emissions by 2030, As a result, Beijing is facing a tremendous energy consumption and carbon emissions pressure (Emanuel and Uffe, 2020; Kanule and Ng'etich, 2020; Mousami et al., 2019; Vimalraj et al., 2019).

Due to the natural resource endowments, China's major energy resource is coal, the consumption of which is 
associated with a series of pollution problems. To meet the surging energy demand, the increasing use of coal will undoubtedly result more pollutions. Recently, the haze phenomenon has already caused significant social concerns in many Chinese cities, especially in Beijing. Research has shown that one of the pollution sources to cause smog is the usage of fossil energy (Boyd et al., 2019). Therefore, Beijing is also facing significant environment pressure to continue its economic development and meet the surging energy consumption requirement. With Beijing's increasing attentions on environmental pollution caused by the usage of fossil energy, Beijing has adopted a number of energy-saving and emission-reduction policies and developed many energy-saving technologies. Beijing has also started increasing the clean energy ratio in energy consumption and restructuring its economic structure to reduce the pollution problems. With these methods, the future demands of fossil energy may reach the inflection point and the peak value. Therefore, identifying when and how many the peak is critical to inform policy makers to plan for Beijing's sustainable.

Energy consumption of a city is influenced by many factors such as population, economic structure and urbanization level, making it a difficult task to accurately predict its peak value and time. This paper examines six development scenarios of Beijing considering these key factors and integrating data from a variety of sources to build a simulation model and scientifically forecast Beijing's future energy usage trend by using the LEAP (Long-range Energy Alternatives Planning System) software.

\section{Literature review}

The methods of the energy demand forecasting and pointed out the methods can be divided into two groups (Suganthi and Samuel, 2012), one is the calculation methods, in which it mainly uses statistical, econometric method, time series method and artificial intelligence method to forecasting the energy demand, and the other is optimization methods with considering the population, GDP, energy productions, energy consumptions and other related factors. In this section, a brief literature review is given from the two types as follows.

\subsection{Calculation forecasting method}

Many scholars employ statistical and econometric methods to forecast energy demand, such as linear regression model (You, 2013), Auto Regressive Integrated Moving Average (ARIMA) (Ediger and Akar, 2007), Grey forecasting model (Xie et al., 2015), The advantages of the traditional forecasting methods are that they are easier to use and the models intuitively explain the relationships between the independent and dependent variables. However, some scholars pointed out that the economic and other independent variables usually deviate from the realizations, so the regression or the econometric model are usually difficult to pass the statistical test (Md. Moinul et al., 2020; Md. Yousuf et al., 2019; Nwankwoala et al., 2020; Saeed et al., 2019).

With the development of artificial intelligence technologies, artificial intelligence forecasting methods, including the artificial neural network (González-Romera et al., 2008), support vector regression (SVR), have been used as new calculation models in forecasting problems widely (Ahmad et al., 2008). Due to determination of the ANN's model structure is a key issue in the energy demand forecasting, some scholars have been employed intelligence algorithms to deal with the problem ( $\mathrm{Li}$ and Su, 2008). From the result performance of the above researches, the hybrid intelligence forecasting methods have been always gotten better forecasting results than traditional forecasting methods or traditional ANNs (Chen et al., 2016).

\subsection{Energy demand plan optimization method}

The energy has a strong relationship of the social livings and economic development, and more energy usages are also increasing the environment's pollution, so the plan of the energy and energy demand forecasting are considered as a complexities problem. some scholars deal with the energy plan or energy demand forecasting problem as an optimization model (Yong et al., 2011), and they pointed out that energy demand forecasting should be considered other factors such as greenhouse gas (GHG) emissions, national economic development (Zhen et al., 2016).

The above researches have made significant contributions to the energy plan or energy demand forecasting, however, as their mentioned, the energy system is a complex system which involves social, economic and environment influences. The aim of this paper is to propose a LEAP system simulation model of the Beijing energy consumption demand forecasting and its carbon emission forecasting, it also includes the peak value of the energy consumption demand and carbon emission. The results can provide an interpretation for the future energy and climates related polices of Beijing city, China.

\section{Beijing's LEAP model}

\subsection{Introduction of LEAP model}

The Long-range Energy Alternatives Planning System (LEAP) calculation model is a bottom-up energyenvironment accounting system analysis software developed by the Stockholm Environment Institute and the University of Boston (Moon et al., 2019). LEAP has a flexible analysis structure for energy planning allowing easy adjust of the model structure to fit the characteristics to the purpose of the study. LEAP is usually used to analyse the different energy future planning or energy consumption under different scenarios, which consider different development levels of economic development (PabloRomero et al., 2018), population growth, energy consumption structure, environment requirement and etc. In the recent decade, LEAP has been widely used for energy demand analysis, energy supply demand analysis, and GHG emissions analysis, it is also used in certain sectors for national and urban scale long-term energy consumption analysis and GHG emissions analysis. The framework of the Beijing Energy forecasting LEAP model is shown in Figure 1. 


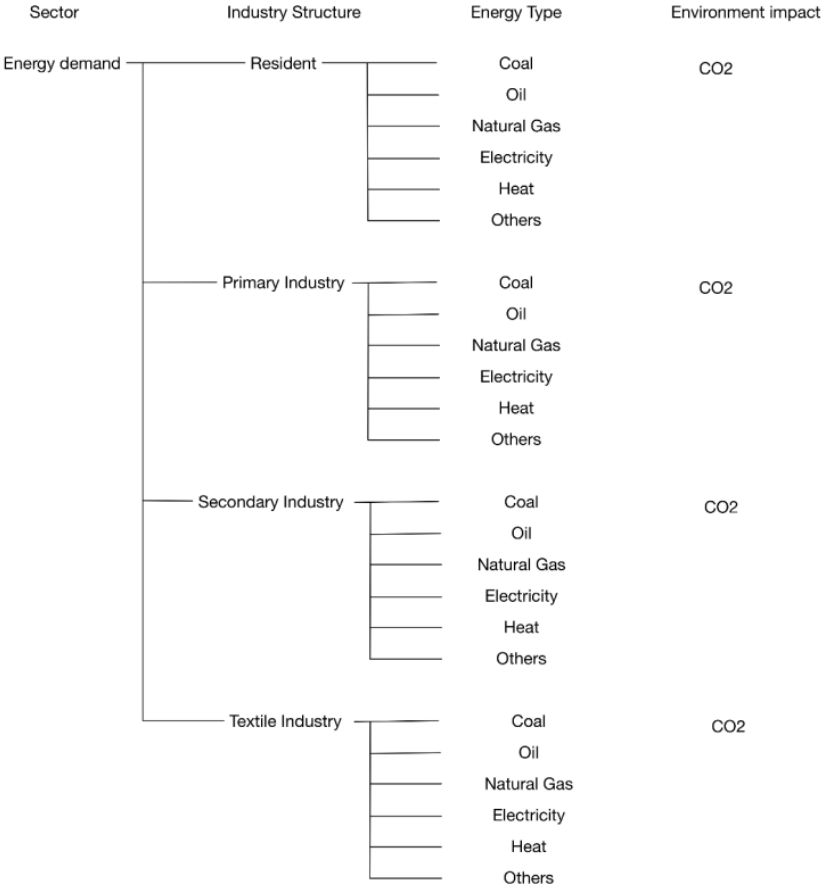

Figure 1. The framework of the Beijing Energy forecasting LEAP model

\subsection{Key parameters and assumptions in different scenarios of LEAP model}

\subsubsection{GDP development}

Beijing's GDP was 1.95 trillion Yuan in 2013, with an economic growth rate at $8.1 \%, 7.7 \%$, and $7.7 \%$ in 2011 , 2012, and 2013, respectively. Because Beijing has not quantified its GDP development goal for the future, we assume that the GDP development rate in Beijing will be the same as what is projected in China's national GDP longterm development plan (Pomponi and Lenzen, 2018). The International Energy Agency (IEA) projected China's longterm GDP growth rate in its report World Energy Outlook 2015 (in Table 1). Additionally, in China's long-term development plan, the Chinese government aims to double China's GDP from 2010 to 2020, which requires China to maintain a GDP growth rate of $6.5 \%$ during this period. According to IEA's projection and China's government's development plan, we developed Beijing's GDP development scenarios S1, S2 and S3 as presented in Table 1. S4, S5, S6 are also used the same assumptions as S1, S2, S3 respectively.

\subsubsection{Population development}

According to Beijing's population development plan, its residents will be 23 million in 2020, peaking sooner than the national population at 24 million in 2040, which is unanimous as the reports of the China's 2050 Urban Population Planning Goals, and Beijing's residents will down to 23 million in 2050.

\subsubsection{Industries structure}

Beijing has realized that industrial structure adjustment from the secondary industry to the tertiary industry is critical for its low carbon development (Wan Mahari et al., 2018). Beijing's tertiary industry has achieved a dominated industry, which is above $76 \%$, so there is not too much space of the tertiary industry's development. According to the economic development long-term plan of Beijing, we assume the proportion of tertiary industry will enhance by $85 \%$, and the proportion of primary industry and the construction will maintain a stable level at $0.75 \%$ and $4.5 \%$, and then the proportion of industry is about $10 \%$.

Table 1. GDP growth rate of China's by IEA and Beijing's scenarios assumption

\begin{tabular}{ccccc}
\hline Year & $\begin{array}{c}\text { IEA (China's } \\
\text { development outlook) }\end{array}$ & $\begin{array}{c}\text { S1/S4 Beijing's standard } \\
\text { development scenarios }\end{array}$ & $\begin{array}{c}\text { S2/S5 Beijing's high } \\
\text { development scenarios }\end{array}$ & $\begin{array}{c}\text { S3/S6 Beijing's low } \\
\text { development scenarios }\end{array}$ \\
\hline $2014-2015$ & $7.20 \%$ & $6.75 \%$ & $7.00 \%$ & $6.5 \%$ \\
\hline $2016-2020$ & $6.25 \%$ & $6.75 \%$ & $7.00 \%$ & $6.5 \%$ \\
\hline $2021-2030$ & $5.30 \%$ & $5.25 \%$ & $5.50 \%$ & $5.00 \%$ \\
\hline $2031-2040$ & $3.20 \%$ & $3.25 \%$ & $3.50 \%$ & $3.00 \%$ \\
\hline $2041-2050$ & $2.73 \%$ & $2.75 \%$ & $3.00 \%$ & $2.50 \%$ \\
\hline
\end{tabular}

\subsubsection{Energy conversion}

From the LEAP frame of Beijing's energy demand model, the energy conversion includes power generation process, oil refining process and heat generation process three parts. Beijing's power generation is mainly by coal-fired generations before 2015 (Ingarao et al., 2018), however, in the future, Beijing's electricity energy will be mainly supplied by external province such as Inner Mongolia autonomous region and Hebei province. In the end of 2015, Beijing only preserve four coal-fired plants and change all the coal-fired plants into gas power plants, and it will not add any a new coal-fired generator until 2020. Therefore, it assumes that the power generation process will not enlarge until 2050 and the coal-fire thermal energy conversion efficiency will enhance from the $42.81 \%$ in 2015 from nearly $50 \%$ in 2050 , in other words, it is equivalent to thermal power generation standard coal consumption from 294 grams tce/(kWh) reduced to 250 grams tce/(kWh).

\subsubsection{Energy intensity}

China has enacted and implemented the report of National Program on Climate Change (2014-2020) in 2014. In the report, the energy intensity is proposed to reduce by $40 \%$ $60 \%$. Because Beijing plans to achieve its carbon emission peak in 2030, its energy intensity will be controlled to stay consistent with China's national level. So, we assume that the energy intensity will decline at a rate of $3 \%$ until 2030 (Stamenkovic et al., 2017), followed by a 1.5\% decline rate from 2031 to 2050 . In total, the energy intensity is expected to decrease by $60 \%$ in 2050 compared to its value in 2005 . In order to compare the impact from controlling the tertiary industry's energy intensity, we assume that the 
energy intensity in S4, S5, S6 will decline $20 \%$ more compared to the above-mentioned values. As a result, the industry's energy intensity will decrease by $40 \%$ compared to its value in 2012 .

\section{Result analysis}

\subsection{Energy demand forecasting results}

\subsubsection{Summarizes of energy demand forecasting result}

Based on the LEAP simulation results, the energy demand forecasting results are calculated from 2014 to 2050 in Figure 2. The results show that the energy demand in all scenarios will peak before 2050. The energy demand peak year is in 2046 in scenario S1 and the peak value is 124.71 Million tce (Mtce). The energy demand peak is 131,74 Mtce in 2048 in scenario S2, while it is 117.52 Mtce in 2044 in scenario S3.

Figure 3 also clearly shows that improving the tertiary industry energy consumption efficiency is a very effective approach to achieve energy saving and emission reduction. The energy demand in scenarios S4, S5, and S6 are lower than those in S1, S2, and S3, respectively. The peaking time in these scenarios is also earlier than scenarios S1, S2, and S3, respectively (Soares et al., 2017). If the tertiary industry can be more energy efficient, the energy demand peak will reach by 2034, 2035, and 2033, which is 12,13 , and 11 years ahead of the energy peak time in S1, S2, and S3, respectively, while the energy demand peak is 111.62 , 115.52 , and 108.25 Mtce, respectively, reduced by $10.13 \%$ $12.32 \%$, and $7.89 \%$, respectively.

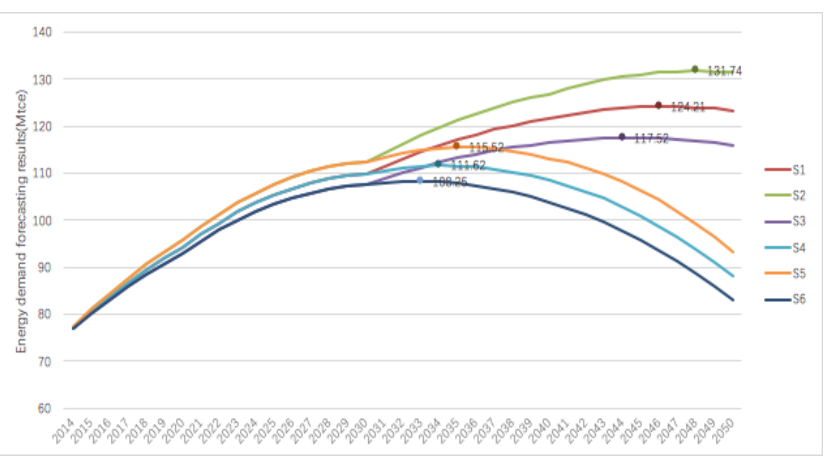

Figure 2. Energy demand forecasting results of different scenarios.

\subsubsection{Energy demand structure forecasting of each sectors results in scenarios}

The energy demand structure of each scenarios is shown in Figure 4. It can be easily seen that the manufacturing industry's energy demand share will reduce, while the tertiary industry's share will increase. With a more efficient tertiary industry (S4-S6), the tertiary industry's share will reduce significantly from above 55\% in S1-S3 to be around $40 \%$. In addition to the tertiary industry, the residential sector will also maintain an increasing share in energy demand in the future.

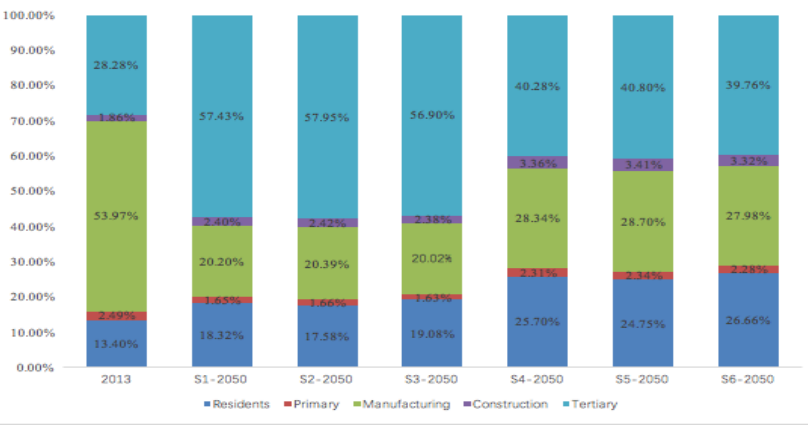

Figure 3. Energy demand structure forecasting of each sectors results in 2050

\section{2. $\mathrm{CO}_{2}$ emission forecasting results}

According to the energy demand forecasting results, there are significant difference in the peak time of the energy consumptions in different scenarios ( $\mathrm{Ng}$ et al., 2018). The peak values are all in the range of $130-140$ Million Metric Tonnes at 2025. The total $\mathrm{CO}_{2}$ emissions will decline significantly by 2050 compared to 2013 value.

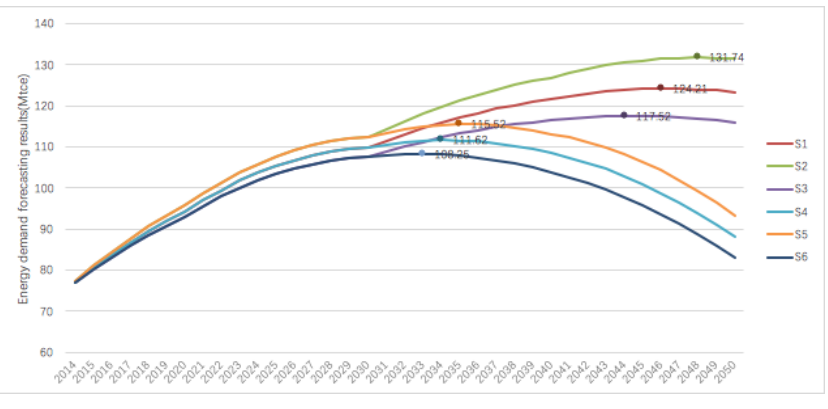

Figure 4. The carbon emissions forecasting result of the different scenarios

\section{Conclusions}

This paper uses LEAP to build an energy demand and consumption forecasting model for Beijing under different economic and technology development scenarios. The results show that Beijing's energy demand peak value will be between 108.25-131.74 Mtce and the peak time will be between 2044-2048. The carbon emissions peak value is between 134-139.38 million tons during 2024-2026.

As LEAP's calculation process, the energy demand structure is the greatest influence factors of the energy demand peak value, peak time and the carbon emissions peak value and peak time. In addition, the strategy of using electricity power to replace the fossil energy is also great for the energy saving and carbon emissions reduction. Additionally, the high efficiency in energy usage of the tertiary industry will significantly accelerate the reduction of the energy consumption and carbon emissions.

\section{Acknowledgments}

This research was conducted with Natural Science Foundation of China (71401054, 71403030), Beijing Planning Project of Philosophy and Social Science (14JGC108) and the Fundamental research funds for the central universities. 


\section{References}

Ahmad A.S., Hassan M.Y., Abdullah M.P., Rahman H.A, Hussin F., Abdullaha H., et al. (2014), A review on applications of ANN and SVM for building electrical energy consumption forecasting, Renewable \& Sustainable Energy Reviews, 33, 102-109.

Boyd A.D., Liu J., and Hmielowski J.D. (2019), Public support for energy portfolios in Canada: How information about cost and national energy portfolios affect perceptions of energy systems, Energy \& Environment, 30(2), 322-340.

Chen J.L., Yang J.X., Zhao J.W., Xu F., Zheng S. et al. (2016), Energy demand forecasting of the greenhouses using nonlinear models based on model optimized prediction method, Neurocomputing, 174, 1087-1100.

Ediger V.Ş. and Akar S. (2007), ARIMA forecasting of primary energy demand by fuel in Turkey, Energy Policy, 35(3), 17011708.

Emanuel J.L. and Uffe J. (2020), The Mineral Nitrogen Distribution from The Combined Free-Range Pig Farming and Energy Crop Production System, Malaysian Journal of Sustainable Agriculture, 4(2), 75-80.

González-Romera E., Jaramillo-Morán M.A. and CarmonaFernández D. (2008), Monthly electric energy demand forecasting with neural networks and Fourier series, Energy Conversion and Management, 49(11), 3135-3142.

Ingarao G., Priarone P.C., Deng Y. and Paraskevas D. (2018), Environmental modelling of aluminium based components manufacturing routes: Additive manufacturing versus machining versus forming, Journal of Cleaner Production, 176, 261-275.

Kanule J. and Ng'etich W. (2020), Numerical modeling of translational dynamics for shallow landslides based on flume tests - special case of spherical-cap-shaped slope sections, Geology, Ecology, and Landscapes, 4(2), 151-158.

Li K. and Su H. (2008), Forecasting building energy consumption with hybrid genetic algorithm-hierarchical adaptive networkbased fuzzy inference system, Energy and Buildings, 42(11), 2070-2076.

Md. Moinul I., Abrar Z.A., Sumaya F.K., Rafiqul I. and Md. Ashraful I.M. (2020), Optimization of Photodegradation Conditions of Rhodamine B in Water with Dye-Sensitized Titanium Dioxide, Journal Clean WAS, 4(1), 28-31.

Md. Yousuf G., Khandakar T.T., Md. Kawser A. and Md Atikul I. (2019), Investigation of Heavy-Mineral Deposits Using Multispectral Satellite Imagery in The Eastern Coastal Margin of Bangladesh, Earth Sciences Malaysia, 3(2), 16-22, DOI: 10.26480/esmy.02.2019.16.22

Moon C., Ahn Y., Lee T., and Hwang Y. (2019), Importance of microbial adaptation for concentrate management in wastewater reuse process, Energy \& Environment, 30(4), 719731.

Mousami P., Prabin A. and Kanti T. (2019), Biology and Control Methods of The Alien Invasive Weed Mikania Micrantha: A Review, Environmental Contaminants Reviews, 2(2), 6-12.

Ng K.H., Cheng Y.W., Lee Z.S., Khan M.R., Lam S.S., and Cheng C.K. (2018), Experimental evaluation and empirical modelling of palm oil mill effluent steam reforming, International Journal of Hydrogen Energy, 43(33), 15784-15793.

Nwankwoala H.O, Harry M.T. and Warmate T. (2020), Assessing Aquifer Vulnerability and Contaminant Plume at Artisanal Refining Sites in Parts of Okrika and Ogu-Bolo Local
Government Areas, Rivers State, Nigeria, Water Conservation and Management, 4(1), 60-64.

Pablo-Romero M.D.P., Pozo-Barajas R. and Sanchez-Braza A. (2018), Analyzing the effects of the benchmark local initiatives of Covenant of Mayors signatories, Journal of Cleaner Production, 176, 159-174.

Pomponi F. and Lenzen M. (2018), Hybrid life cycle assessment (LCA) will likely yield more accurate results than processbased LCA, Journal of Cleaner Production, 176, 210-215.

Saeed U., Shamim U. and Muhammad A. (2019), Study of Fenced Conservation Compared to Land Exposed to Grazing in Dera Ghazi Khan (Pakistan), Earth Sciences Pakistan, 2(2), 5-8

Soares M., Bianco S., Finoto E.L., Bolonhezi D. and Albuquerque J. (2017), Phytosociological study on the weed communities in green sugarcane field reform using conservation tillage and oilseed crops in succession, Applied Ecology and Environmental Research, 15(3), 417-428.

Stamenkovic U.M., Andrejic G., Mihailovic N. and Sinzar-Sekulic J. (2017), Hyperaccumulation of ni by alyssum murale waldst. \& kit. from ultramafics in Bosnia and Herzegovina, Applied Ecology and Environmental Research, 15(3), 359-372.

Suganthi L. and Samuel A.A. (2012), Energy models for demand forecasting-A review, Renewable and Sustainable Energy Reviews, 16(2), 1223-1240.

Vimalraj P.G., Parag M.D. and A.U. (2019), Developmental Human Interface Due to Train Collision of Asian Elephant (Elephas Maximus) In Western Circle Forest Division, Uttarakhand, India, Environment \& Ecosystem Science, 3(2), 17-19.

Wan Mahari W.A., Chong C.T., Lam W.H., Anuar T.N.S.T., Ma N.L., Ibrahim M.D. and Lam S.S. (2018), Microwave co-pyrolysis of waste polyolefins and waste cooking oil: Influence of $\mathrm{N}_{2}$ atmosphere versus vacuum environment, Energy Conversion and Management, 171, 1292-1301.

Wu Z. and Xu J. (2013), Predicting and optimization of energy consumption using system dynamic-fuzzy multiple objective programming in world heritage areas, Energy, 39, 19-31.

Xie N.M., Yuan C.Q. and Yang Y.J. (2015), Forecasting China's energy demand and self-sufficiency rate by grey forecasting model and Markov model, International Journal of Electrical Power \& Energy Systems, 66, 1-8.

Yong Z., Cai Y.P., Huang G.H. and Dai J. (2011), A Review on optimization modeling of energy systems planning and ghg emission mitigation under uncertainty, Energies, 4(10), 16241656.

You J. (2013), China's challenge for decarbonized growth: Forecasts from energy demand models, Journal of Policy Modeling, 35(4), 652-668.

Zhen J.L., Huang G.H., Wei L., Wu C.B. and Liu Z.P. (2016), An optimization model design for energy systems planning and management under considering air pollution control in Tangshan City, China, Journal of Process Control, 47, 58-77. 